\title{
LITERATURA FANTÁSTICA \& CONTOS DE FADAS (2018), DE ANDRÉ DE SENA (ORG.)
}

Eduardo Melo França (UFPE)

Recebido em 04 set 2019. Eduardo Melo França é Professor Adjunto do Aprovado em 11 set 2019. Departamento de Letras da Universidade Federal de Pernambuco (UFPE). Doutor em Teoria da Literatura pelo Programa de Pós-graduação em Letras da UFPE com a tese "A recepção da literatura brasileira em Portugal no século XIX e o problema da sua autonomia". Mestre em Teoria da Literatura pelo mesmo programa com a dissertação "Ruptura ou amadurecimento? Uma análise dos primeiros contos de Machado de Assis". Áreas de interesse: Literatura brasileira, Romantismo, Literatura e humor, Machado de Assis e diálogos entre Literatura e Psicanálise. 
A pluralidade de abordagens que observamos entre os ensaios que compõem a coletânea Literatura fantástica e contos de fada, resultado do 6으 Congresso de Literatura Fantástica de Pernambuco (CLIF-PE), organizado pelo Prof. Dr. André de Sena e publicado

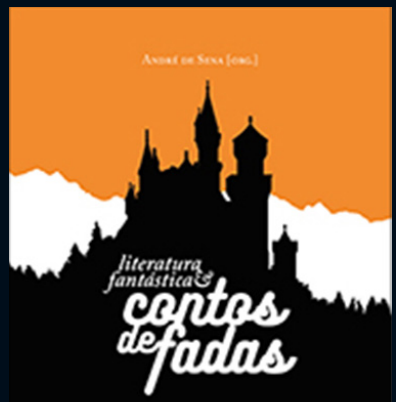
em 2018 pela Editora da Universidade Federal de Pernambuco (UFP), não 皮 apenas demonstra o atual estado de vitalidade que envolve os estudos relacionados ao fantástico e ao maravilhoso, como também nos permite observar em todos os autores envolvidos na publicação um interessante entrelaçamento entre uma sólida postura conceitual-teórico e um criativo olhar crítico voltado especificamente para as diferentes obras tratadas em cada ensaio. Em comum entre todos os trabalhos, o conto de fadas, tema central da sexta edição do CLIF, realizado em 2016, na Universidade Federal de Pernambuco e organizado pelo núcleo Belvidera.

Os estudos realizados pelos autores dessa coletânea acerca de escritores como Lewis Carroll, Mia Couto, Edgar Allan Poe, Lygia Fagundes Telles, Théophile Gautier e Lord Dunsany, ressaltam a necessidade de reconhecermos os contos de fadas como uma espécie de produção literária muito menos relacionada às histórias ingênuas, felizes, harmônicas, otimistas e próximas às produções infantis da Disney e muito mais expressivas no que diz respeito aos medos, desejos de descoberta, inquietações, angústias e trajetos percorridos pelo ser humano ao longo da vida. Em comum entre todos os ensaios, 
a necessidade de admitir que o contato com o mundo maravilhoso e fantástico não representa apenas uma suspensão do juízo crítico, uma reafirmação ficcional ou uma liberação momentânea, psíquica e intelectual, das regras que organizam o mundo real. Esse mundo do faz de conta, das fadas, dos mitos, deuses, monstros, noites e seres estranhos em vários momentos dizem de forma muito mais criativa e contundente sobre nossa condição humana do que muitas histórias pretensamente realistas.

Uma das impressões mais marcantes que fica diante das diversas formas de abordar o conto de fadas com as quais nos deparamos ao longo dessa coletânea é a de que o maravilhoso, o fantástico, o simbólico, o mito, as lendas e tudo mais que dá cor e preenche esse mundo de fantasias existe porque de alguma forma a razão cotidiana, a res pragmática ou processo aparentemente definitivo de naturalização das palavras e coisas nem sempre se mostra capaz de apreender ou expressar os sentimentos e desejos que de tão profundos e fundamentais escapam às ferramentas mais usuais da linguagem e da consciência.

O livro é composto por oito artigos e todos eles girando em torno dos contos de fada. Nesse trajeto, diferentes autores, com diferentes estilos e projetos literários, aparecem, nessa publicação, reunidos pelo signo da inventividade, da imaginação, pela capacidade de ultrapassar as barreiras impostas pelo limite da razão e mergulhar em outras dimensões imagéticas e linguísticas, nas quais os personagens, os narradores e os leitores são convidados a olhar para a sua realidade de uma nova forma, admitindo-a muito mais misteriosa, colorida ou obscura e menos racional. De Karin Volobuef, temos o ensaio intitulado "Viagem e maravilhoso: 
trajetos no imaginário"; de Flavio García, "Entre contos de fadas e enfados na ficção de Mia Couto"; de Regina Michelli, "Os contos de fadas no cenário da tradição e da contemporaneidade: questões de gênero"; de Victor Vitório de Barros Correia, "Além dos campos que conhecemos: Lord Dunsany"; de Letícia Raiane dos Santos, "Contos de fadas e novelas de cavalaria arturianas: relações possíveis"; de Imara Bemfica Mineiro, "Burlar o implacável topia do corpo (Através do espelho e no país das Maravilhas): leituras de Foucault e Alice; de André de Sena, "Simbolismo, fantástico e estranhamento num conto de Poe"; por fim, de Sarah Burnauutzki, “A tapeçaria enigmática nos contos fantáticos 'Omphale'(1834) de TheóphileGautier e 'A caçada' (1965) de Lygia Fangundes Telles".

Ainda que todos os ensaios mereçam leituras atentas e cuidadosas, destaquemos alguns deles. O ensaio "Viagem e maravilhoso: trajetórias no imaginário", de Karin Volobuef, tem o mérito de problematizar os possíveis significados das diversas possibilidades de trajetos e viagens que envolvem o herói em obras marcadas pelo maravilhoso. Recorrendo a Lucie Armitt, a autora ressalta que esse herói é sempre um estrangeiro, um sujeito desorientado e perdido, longe de casa, procurando um caminho de volta, seja ele para um lugar que existe e onde se locomovendo pode-se chegar, dentro da lógica desse mundo ficcional, ou que existe muito mais dentro de si, significando, por exemplo, antes de qualquer coisa, um encontro com si mesmo. Ainda que mencione algumas obras que fazem parte do mundo maravilhoso e dos contos de fada, o fio da meada é o conto "O diabo e os três fios de cabelo". Tal como boa parte dos autores da coletânea, Volobuef faz uso de algumas categorias propostas por Vladmir Propp, no seu Morfologia 
dos contos maravilhosos, para definir o herói do conto de fadas e como ele se relaciona com sua viagem. A autora, conciliando diversas referências bibliográficas, conclui que o herói dos contos de fadas, diferentes dos míticos, normalmente é um sujeito especialmente frágil, órfão, pobre e quase sempre creditado como um tolo. Ainda assim, precisa vencer uma série de dificuldades e carências, muitas vezes necessitando se deslocar para terras distantes.

Mesmo que o protagonista de "O diabo e os três fios de cabelo" tenha realizado diversas viagens desde muito jovem, deslocando-se no espaço e tempo, o mais importante, segundo a autora, é entender que o percurso do herói, antes de tudo, diz respeito ao da vida. Assim, o final feliz, típico dos contos de fada e magia, após vencer desafios e inclusive a morte, corresponde à chegada à vida adulta de alguém jovem - este seria, segundo a autora, o sentido antropológico do final da história, quando o herói casa e assume a função de Rei. Por fim, vale destacar a comparação feita pela autora entre os contos de fadas e os mitos da Antiguidade Clássica. Assim como Ulisses desceu ao Hades para saber por Tirésias como retornar à Ítaca, também o personagem de "O diabo e os três fios de cabelo" é auxiliado primeiro por uma anciã na cabana dos ladrões e depois por outra anciã na morada do Diabo. Segundo Volobuef, as duas anciãs correspondem aos ancestrais míticos, dotados de conhecimento e visão profética.

Já André de Sena, com o artigo "Simbolismo, fantástico e estranhamento num conto de Poe", parece ser, dentre os autores, aquele que situa o conto de fadas num painel literário mais amplo. Segundo o estudioso, o conto "A ilha da fada", de Edgar Allan Poe, é possivelmente o texto mais estranho dentro da sua 
produção, na qual elementos grotescos e fantásticos prevalecem de forma inconteste. Sua análise parte de princípios que ressaltam a dificuldade de situar com exatidão, entre o Romantismo ou Simbolismo, os aspectos fantásticos do conto de Poe. O primeiro ponto destacado como decisivo no conto é a autorreferencialidade da obra. Após evidenciar um comentário do narrador do conto no qual se estabelece um paralelo entre a música e a literatura em termos de ressaltar um possível caráter imanentista e autorreferencial nas duas artes, André de Sena, ainda para mostrar como "A ilha da fada" parece navegar em mares não muito exatos entre o Simbolismo, o Romantismo e o Fantástico, destrincha o conto em três gradações no tocante à referencialidade.

No primeiro momento, o personagem central, numa dicção romântica ou mesmo "fantástica", como diz o pesquisador, fala em primeira pessoa e se vê na natureza. Na segunda parte, se iniciam as passagens autorreferenciais, e, por fim, no que ele considera o terceiro momento, podemos observar o "imanentismo simbólico" (2018, p.152), quando os referentes se desligam de sua referencialidade, gerando sugestão pura. Um ponto importante a se destacar no ensaio é a perspicácia com qual o autor aponta a passagem de um olhar romântico para outro fantástico a partir do modo como o narrador se relaciona com a natureza. Como destaca André, "se Rousseau romantiza a paisagem, Poe a torna fantástica, para isso fazendo uso, num contínuo, como se verá, de um processo de perda gradual de referencialidade objetiva e mimética, bem como de imagens ligadas ao universo dos contos de fadas" (2018, p.153). Outra aproximação apontada é que o narrador encantado com a localidade tem o ensejo de nela 
"dormitar", o que gera uma típica ambiguidade onírica igualmente presente no fantástico.

A análise ainda tem a delicadeza de perceber a sutil passagem no mesmo conto do que seria um primeiro momento marcado pela imaginação romântica, com ainda elementos referenciais, para uma segunda mais simbolista, na qual surge a apresentação de imagens sugestivas e autorreferenciais. Segundo o estudioso, isso nos permitiria reconhecer na "A ilha da fada" um "trecho-fronteira" (2018, p.157) entre o Romantismo e o Simbolismo. Ainda que André de Sena não ressalte isso, sua análise não deixa dúvida de que podemos admitir esse "trecho-fronteira" exatamente como um índice do lugar que a obra de Poe ocupa no cenário oitocentista, reafirmando a criação romântica, sua profundidade obscura e já lançando mão de elementos tão característicos do simbolismo, como a formalização de um quadro no qual a linguagem ganha primazia, referindo-se a si própria através de toques de sinestesia e melopeia.

A possibilidade de reconhecer nessa narrativa a antecipação de procedimentos que posteriormente se tornariam essenciais para o Simbolismo é reafirmada quando o conto retrata uma fada dentro de uma canoa dando voltas ao redor da ilha, que tem uma parte iluminada e outra escurecida. Ao se perguntar qual o significado ou a metáfora desse movimento, André de Sena diz não ter dúvidas em estar diante do "símbolo e da escrita simbolista" (2018, p.158). A cena da canoa, segundo o pesquisador, seria uma antecipação de quase duas décadas de procedimentos estilísticos empreendidos por Baudelaire em poemas como "Harmonia da tarde", publicado em As flores do mal. 
É possível afirmarmos que uma das grandes contribuições desse artigo seja o reconhecimento de que na prosa de Poe, num mesmo conto, haveria uma passagem de um Romantismo transcendental e projetivo do eu autorreferencial para a exploração de traços essenciais do Simbolismo, como o enigmatismo, a pluralidade significadora das palavras e objetos e a penumbra de mistério que atravessa todo o conto. Por consequência, "A ilha da fada", assim com um poema baudelairiano, traz consigo a mesma sensação de impossibilidade de se alcançar uma interpretação final e completa do conto.

A questão seguinte colocada no artigo é a possibilidade de reconhecermos alguma possível relação entre os princípios simbolistas e a literatura fantástica. Para André de Sena, seguindo a classificação proposta por Charles Nodier, "A ilha da fada" seria o que se pode chamar de "história fantástica vaga", um relato capaz de manter o leitor numa dúvida sonhadora e melancólica, acalentando-o numa melodia, como se estivesse num sonho. Nesse mesmo raciocínio, André de Sena lança mão da classificação proposta por Roger Bozzeto (1980), que considera o fantástico como uma experiência de natureza onírica, capaz de afastar o sujeito do cotidiano banal e burguês, elevando-o a uma nova sensibilidade estética e criativa. Ainda seguindo na sua pesquisa sobre as possíveis relações agora entre os modos fantástico e simbolista, o artigo comenta as principais contribuições de autores clássicos sobre o tema, partindo de Charles Nodier, passando por Freud, Pierre-Georges Castex, Louis Vax, Roger Caillois, Irène Bessière, Remo Ceserani, Rosalba Campra, Tzvetan Todorov, David Roas, Maria João Simões, Susana Reisz e Tsuyoshi Aino. 
Por fim, a resposta fundamental do artigo retorna para ser respondida: quais as aproximações entre "A ilha da fada" e os contos de fada? Ainda que a resposta não seja enunciada diretamente, admitindo a relação entre os contos de fada e o fantástico, André de Sena parece defender a ideia de que o conto de Poe seria uma junção entre os modos simbolista e fantástico, indo além das definições propostas por Propp, apresentando de modo definitivo uma sucessão de imagens imanentistas, além da hesitação, a sublimação do real transfigurado pela fantasmagoria, a autossugestão e o discurso indireto de imagens.

No artigo "Burlar a implacável topia do corpo (Através do Espelho e No País das Maravilhas): leituras de Foucault e Alice", de Imara Bemfica Mineiro, é possível notar um debate que justapõe o pensamento de Foucault sobre o corpo tópico e utópico, as heterotopias e a obra de Lewis Carroll. A partir da forma como o corpo aparece em no País das Maravilhas e Através do Espelho, a autora projeta um debate foucaultiano acerca do corpo na sua (1) dimensão mais real, material e cotidiana, confrontando-a com sua (2) dimensão utópica, além de tomá-lo como (3) heterotopia, um espaço de inquietações sobre si mesmo, pondo em questão sua relação com nomes, espaço e tempo.

A primeira consideração importante feita pela autora é a de que, apesar do próprio título da obra se referir a algo que nos remeta ao maravilhoso - Alice no país das maravilhas -, a obra seria mais adequadamente considerada fantástica, pois provoca inquietação e com isso estabelece um diálogo problematizador com a realidade. Resolvido o primeiro problema, o segundo ponto a ser encarado é a relação entre Alice e os contos de fada. 
A primeira observação interessante da autora é que, de certa forma, os contos de fada, sendo marcados pelo maravilhoso, estariam do lado oposto ao fantástico. Pois, diferentemente da inquietude e problematização da realidade proposta pelo fantástico, os contos de fada, ingênuos e imersos num mundo de mentira, tal como definidos por Marcia Romero Marçal, ofereceriam pouco ou quase nenhum atrito com o mundo extratextual. Contudo, a coisa não é bem assim e a pesquisadora nos lembra que os contos de fadas não se resumem ao modelo comumente oferecido pela Disney, sempre harmonioso e otimista. De outra forma, ele pode trazer aspectos violentos, aterrorizantes, mágicos e voluptuosos, nos remontando mais às tradições orais e populares do que ao processo civilizatório iluminista.

A pesquisadora acredita que apesar de Alice não ter suas origens nos contos populares, tão pouco ela deixa de oferecer todos os ruídos necessários para desnortear e inquietar o leitor: jogos de linguagem, nonsense, inversão das relações causais, assombro e contato com o desconhecido. O terceiro importante ponto é a possibilidade de reconhecermos o mundo encontrado por Alice na toca do coelho ou por detrás do espelho menos como uma utopia, enquanto espaço longínquo, distante e por isso menos perturbador, e mais como uma heterotopia, pois ao sugerirem a quebra usual das relações lógicas estariam muito mais próximos de desestabilizar nosso entendimento usual de leitura.

Entretanto, é a consciência de um corpo real, limitado e irremediável que leva o sujeito a desejar e projetar fantasias, irrealidades, a inventar um corpo incorporal e utópico. A consciência da falta, do limite, da impossibilidade e da prisão física representada 
pelo corpo real é a mola mestra que leva o sujeito a imaginar uma condição na qual toda a lógica, cultura, regra e limitações que envolvem e constroem seu corpo real seja substituída por uma outra que projeta e aponta para a busca pela satisfação de tudo aquilo que a ordem do cotidiano escamoteia. Se somos, antes de qualquer coisa, corpo, somos corpo e desejo. Estes corpos, diz Foucault, na medida em que são utópicos, estão fora de lugar "e se transportam tão rápido quanto a luz, onde as feridas se curam com o bálsamo maravilhoso com a duração de um relâmpago, o país onde se pode cair de uma montanha e reerguer-se vivo, o país onde se é visível quando se quer, invisível quando se desejar" (2003, p.8). Esse país, diz Foucault, é o dos duendes, mágicos e fadas - e, complementa Imara Bemfica, o do País das maravilhas e Através do espelho. Foucault não fala, mas achamos que vale a pena reforçar que esse país dos corpos livres e utópicos não precisaria ser o maravilhoso, fantástico ou de fadas, mas qualquer um que traga consigo as marcas das projeções dos desejos mais íntimos e subversivos; um país, um lugar ou um não-lugar no qual, como diz Lacan, vigore a ética do desejo e não o da cultura. Esse novo mundo utópico é, na verdade, o mundo da liberdade, aquele que suprime as dificuldades impostas pelo tempo, pelas distâncias e pelas regras.

Contudo, Imara Bemfica reforça que nem tudo é maravilha no novo mundo no qual Alice se encontra mais ou menos perdida e querendo, sem saber como, se achar. Basta notarmos o seu incômodo diante do puxa-encolhe ao qual seu corpo está submetido para logo entendermos que o País das maravilhas, não tão harmônico, estaria mais para uma heterotopia foucaultiana do que para uma utopia, livre de polêmicas ou desconfortos, tal como caracterizada por Rancière. 
Vale destacar ainda que a autora sublinha que, no processo de construção de espaços heterotópicos vividos por Alice, dois objetos são privilegiados. O primeiro, o espelho: "esse lugar sem lugar e, ao mesmo tempo, multiplocador de lugares, que opera na inversão dos ângulos e subverte o esperado nas relações entre o aqui e o ali, cavando um fosso infindável na superfície plana de seu avesso" (2018, p.135). O segundo, seria o jardim, "espaço que guarda uma atmosfera mágica, legada desde tempos remotos e que se abre, nas narrativas de Carroll, a uma multiplicidade de dimensões lúdicas" (2018, p.135).

Por fim, fica clara a ideia proposta pela autora de que a obras de Carroll mostram como as heterotopias, mais do que as utopias, trazem consigo um potencial revelador e desnaturalizador da realidade. O efeito de consternação diante do real produzido pelo contato com um novo mundo possível, no qual as regras, o corpo, as ideias e os sentimentos são novos e nos ensinam a lidar e a admitir o impossível não apenas como um desejo, mas como uma postura prática e emocional diante da vida. O nonsense várias vezes observado nas aventuras de Alice não diz apenas sobre esse novo mundo no qual tudo é surpreendente e quase ao avesso, fala também sobre a necessidade de admitirmos em certa medida a perda do respeito ao que parecem ser os limites irredutiveis da realidade e da vida.

\section{REFERÊNCIAS}

SENA, André de (Org.) (2018). Literatura fantástica \& contos de fadas. Recife: Ed. UFPE. 